\title{
A CONSTITUIÇÃO DA IDENTIDADE DOCENTE ENTRE A PROJEÇÃO DO MERCADO E AS LUTAS DO COMUM
}

\author{
Derlan Trombetta \\ Universidade Federal da Fronteira Sul - UFFS, Brasil \\ Maria Beatriz Luce \\ Universidade Federal do Rio Grande do Sul - UFRGS, Brasil
}

\begin{abstract}
Resumo
Neste artigo examinamos como a formação de professores assumiu centralidade nas reformas educacionais contemporâneas. Referenciados em Pierre Dardot e Christian Laval (2016) e Stephen Ball (2002 e 2005), analisamos a forma pela qual a racionalidade neoliberal se impôs nas políticas de formação de professores, sob os desígnios do gerencialismo e da performatividade como tecnologias políticas. Guiados pela concepção de comum como princípio político alternativo (Dardot; Laval, 2017), mostramos que, entretanto, há um movimento global de resistência a tais tecnologias políticas neoliberais, no Brasil protagonizado pelo Movimento dos Educadores, que há quatro décadas luta pela qualificação da formação de professores e valorização profissional a partir da perspectiva histórico-crítica, expressa na Base Comum Nacional e incorporada nas resoluções $\mathrm{CNE} / \mathrm{CP}^{\circ}$ 01/2006 e n ${ }^{\circ}$ 02/2015.
\end{abstract}

Palavras-chave: Formação de professores; Identidade docente; Gerencialismo; Base Comum Nacional.

\begin{abstract}
In this article we examine how teacher education became a central issue in contemporary educational reforms. Referenced in Pierre Dardot and Christian Laval (2016) and Stephen Ball (2002 and 2005), we analyze the way neoliberal rationality has ascended within teacher education policies, by means of managerialism and performativity as political technologies. Lead by the conception of common as an alternative political principle (Dardot; Laval, 2017), we show that, nonetheless, there's a global movement of resistance to such neoliberal political technologies, which in Brazil has been carried out by the Movement of Educators. For as long as four decades, they fight for the enhancement of teacher education and for teaching as a valued professional career through the historical-critical perspective, supported in the Common National Basis and in the National Council on Education guidelines - CNE/CP n ${ }^{\circ} 01 / 2006$ and $n^{\circ} 02 / 2015$.
\end{abstract}

Keywords: Teacher formation; Teacher identity; Managerialism; Common National Basis. 


\title{
Introdução
}

\author{
"A única práxis instituinte emancipadora \\ é aquela que faz do comum \\ a nova significação do imaginário social."
}

(Dardot; Laval, 2017, p. 478)

Neste artigo analisamos o contexto de influência das políticas de formação de professores, para apresentar contornos da sua atualidade dialogando com alguns referenciais teóricos da área. Apresentamos a influência de elementos econômicos, sociais e políticos, a ação dos grupos de pressão na formulação das políticas e como estas têm produzido novas identidades docentes. Nessa investigação operamos com os referenciais teóricometodológicos do pesquisador britânico da sociologia das políticas educacionais, Stephen J. Ball, e dos franceses Pierre Dardot e Christian Laval para, a partir deles e com outros autores, situar as políticas de formação de professores no contexto em que as políticas públicas são influenciadas pela nova "razão do mundo" - o neoliberalismo - mas também por movimentos de resistência a essa racionalidade homogeneizadora, que buscam a autonomia da docência a partir de lutas e compromissos comuns.

Reconhecemos que, a partir da racionalidade hegemônica neoliberal que se consolidou no final do século XX, organismos internacionais ligados aos interesses do mercado passaram a propor políticas educacionais, de maneira geral, e sobre a formação de professores, em especial, com o objetivo de produzir uma padronização do ensino escolar e da formação docente em escala global, referenciada num projeto homogeneizador e instrumentalista, que prioriza as habilidades técnicas e práticas, colocando em segundo plano a formação intelectual, os compromissos políticos, os valores morais e culturais, os projetos de vida dos professores e a igualdade de condições para as maiorias sociais.

Stephen J. Ball nos auxilia neste percurso, porque é uma referência na análise de políticas educacionais, em função de sua importante contribuição teórico-metodológica para compreendermos o contexto em que essas são produzidas. Aproximou-se dos escritos de Michel Foucault, quando mostra que estamos vivendo numa episteme neoliberal que perpassa todos os campos da vida social com um conjunto de verdades diretamente vinculadas à lógica gerencialista e meritocrática, de mercado - numa normatividade que submete o Estado e os indivíduos.

O novo quadro de políticas, em geral, e a forma do mercado, em particular, constituem o novo ambiente moral tanto para consumidores quanto para produtores - ou seja, uma forma de "civilização comercial" (Benton, 1992, p. 118). No seio deste novo ambiente moral, as escolas e as universidades são induzidas a uma "cultura de auto-interesse" (Plant, 1992, p. 87). As motivações pessoais sobrepõem-se aos valores impessoais. Os "procedimentos de motivação" inseridos neste novo paradigma de gestão pública elicitam e geram os impulsos, 
relações e valores que fundamentam o comportamento competitivo e a luta pela vantagem. (Ball, 2001, p. 106)

Em entrevista a Mainardes (2015, p. 162), Ball chama a atenção para a necessidade de o pesquisador de políticas ter consciência de quais são os "pressupostos de poder, de subjetividade, de verdade" em que opera, para poder olhar além daquilo que chama de "epistemologia de superfície", a que fica presa na aparência dos dados. Essa reflexão prévia é necessária para que possa empreender uma "epistemologia profunda", enxergar as políticas, não como algo linear, mas como "um processo social relacional, um processo temporal discursivo", ou seja, um movimento permeado de "relações de poder", e, assim, compreender as "características sistêmicas neoliberais" nelas presentes. Mesmo sem a pretensão fazê-lo, Ball (1994), Bowe e Ball (1992), Bowe, Ball e Gold (1992) e Ball, Maguire e Braun (2016) oferecem um conjunto de ferramentas conceituais e analíticas que nos ajudam compreender a realidade social complexa e desordenada, por conseguinte, a olhar para as políticas em diferentes contextos.

Em diálogo com Dardot e Laval (2016), vemos que o neoliberalismo não pode ser encarado como uma mera ideologia ou uma política econômica orientada por essa ideologia. A partir da leitura da obra Nascimento da Biopolítica, de Foucault (2008), os autores mostram que o neoliberalismo produziu uma forma muito mais eficiente de governar a economia e a sociedade, gerando uma nova governamentalidade ${ }^{1}$, uma nova maneira de dirigir, não só o Estado e a economia, mas, também, "conduzir a conduta” de todos os indivíduos. "É um sistema normativo que ampliou a sua influência ao mundo inteiro, estendendo a lógica do capital a todas as relações sociais e a todas as esferas da vida" (Dardot; Laval, 2016, p. 8). Desta forma, o neoliberalismo se constituiu na razão do capitalismo contemporâneo, se desvencilhando tanto das amarras do liberalismo clássico, quanto do estado de bem-estar keynesiano, para construir uma "norma geral da vida" e dirigir a conduta de todos.

Não se trata mais de perguntar como, de maneira geral, as relações capitalistas impõem-se à consciência operária como "leis naturais evidentes"; trata-se de compreender, mais especificamente, como a governamentalidade neoliberal escora-se num quadro normativo global que, em nome da liberdade e apoiando-se nas margens de manobra concedidas aos indivíduos, orienta de maneira nova as condutas, as escolhas e as práticas desses indivíduos (Dardot; Laval, 2016, p. 21).

Neste contexto, percebemos como se apresentam os diferentes interesses em torno das políticas públicas para a formação de professores e como estas influenciam as identidades docentes. Ao identificarmos o campo político majoritário, vinculado aos interesses ideológicos e valores do neoliberalismo, que pretende reformar os professores para conformá-los aos interesses do mercado, notamos que advogam a simplificação e o barateamento do processo de formação, porque para eles é suficiente professores treinados para desenvolver nos estudantes habilidades e competências prescritas por um currículo padronizado exigido pelo mundo do trabalho. Postulam a gestão gerencialista, que se utiliza 
da performatividade como motriz das políticas de formação de professores, mediante um processo permanente de monitoramento, avaliação e premiação. No entanto, há um processo de resistência a este modelo de formação de professores, mobilizado por setores da sociedade que concebem a educação numa perspectiva crítica e emancipatória e veem nela uma ferramenta para a justiça social e a construção de espaços e processos comuns. Defendem uma formação mais abrangente dos profissionais da educação, para que estes tenham mais autonomia intelectual, compreendendo a complexidade das relações pedagógicas no ambiente escolar e as relações da escola com o meio social.

Com efeito, Dardot e Laval (2017) propuseram um conjunto de reflexões que nos leva a pensar para além das limitações impostas pelo neoliberalismo, abrindo possibilidades para transformações de caráter revolucionário, em processo político instituinte de uma nova realidade. Isso se daria por meio da "atividade coletiva autônoma" articulada "a práticas de natureza muito diversa", ou seja, quando a sociedade tem no eixo central da sua ação o princípio do comum, como princípio político alternativo. Nessa perspectiva, a ação humana prática é sempre uma atividade com o outro, que envolve cooperação e reciprocidade. O comum não é um bem ou objeto sujeito à vontade individual ou uma virtude que possa ser compartilhada. É um princípio político que deriva de/em uma atividade prática das pessoas engajadas na mesma tarefa de produzir comuns, pois

somente a atividade prática dos homens pode tornar as coisas comuns, do mesmo modo que somente essa atividade prática pode produzir um novo sujeito coletivo, em vez de afirmar que tal sujeito preexista a esta atividade na qualidade de titular de direitos. Se existe 'universalidade', só pode tratar-se de uma universalidade prática [...] O comum é o princípio político a partir do qual devemos construir comuns e ao qual devemos nos reportar para preservá-los, ampliá-los e lhes dar vida. É, por isso mesmo, o princípio político que define o novo regime de lutas em escala mundial (Dardot; Laval, 2017, p. 53-54).

Aliás, para Dardot e Laval (2017b, p. 9-10), o comum é um princípio político porque a política é "a atividade de deliberação pela qual os homens se esforçam para determinar juntos o que é justo, bem como a decisão e ação decorrentes dessa atividade coletiva”. É, portanto, compreender que a participação política é "ao mesmo tempo obrigação e atividade". Essa obrigação se origina do "agir comum" e se fortalece no compromisso coletivo de construir as próprias regras de suas atividades. O comum não é um objeto, “está aquém de qualquer objetivação". Ele é o princípio que move a busca pelo "bem comum".

Desta perspectiva, não podemos conceber a educação e a formação de professores, de modo particular, como um processo individual e "apropriável" como propõem no neoliberalismo ao focar o processo político no indivíduo através de estratégias de governamento como o gerencialismo e a performatividade. Dardot e Laval (2017b), ao proporem o comum com novo princípio político para a ação humana, acreditam que "a obrigação política procede inteiramente do agir comum, extrai força do compromisso prático que une todos os que elaboraram juntos as regras de sua atividade" (p.10). Assim, um espaço 
comum, como a educação, não pode ser apropriado por interesses privados porque deve ser "reservado ao interesse comum". Para os autores cabe "à práxis instituinte determinar o que é inapropiável" posto que

Instituir o inapropriável é subtrair uma coisa à apropriação-pertencimento para realizar melhor a sua apropriação-destinação. Em suma, é proibir de se apropriar dela para a apropriar melhor a sua destinação social - por exemplo, a terra às necessidades de alimento. É regrar seu uso sem fazer-se proprietário dela, isto é, sem se arrogar o poder de dispor dela como dono. Por isso, mesmo compreendendo que podemos continuar a falar de "bens comuns" como palavra de ordem na luta, será preferível abster-se de falar de "bens": não existem "bens comuns", existem comuns que devem ser instituídos. (Dardot; Laval, 2017b, p. 11)

A emergência do "comum" como uma categoria de análise, fundamentada no princípio político de contestação das concepções técnicas, jurídicas e econômicas predominantes na sociedade atual e como um ato político instituinte de um projeto articulador das lutas políticas na sociedade, fornece grandes possibilidades para compreendermos o atual contexto e produzirmos transformações. Se pretendemos superar o neoliberalismo e construir possibilidades de existência para além do egoísmo social e da negação da solidariedade,

[...] temos que desenvolver uma capacidade coletiva que ponha a imaginação política para trabalhar a partir da experimentação e das lutas do presente. O princípio do comum que emana hoje dos movimentos, das lutas e das experiências remete a um sistema de práticas diretamente contrárias à racionalidade neoliberal e capazes de revolucionar o conjunto de relações sociais [...] precisamos trabalhar por uma outra razão do mundo (Dardot; Laval, 2016. p. 9).

Como o princípio político do comum emana dos movimentos e das lutas contra a racionalidade instrumental e homogeneizante do neoliberalismo, o comum se torna um espaço aberto para a diferença e para aglutinar os movimentos que buscam afirmar suas identidades, seja de gênero raça/etnia, sexualidade, entre outras, para construir as relações em outras bases. Porém, Dardot e Laval (2017) não acreditam que possamos confrontar a razão neoliberal, que é "uma estrutura social total", apenas com movimentos identitários ou de "contraconduta". Para eles, precisamos de um "projeto de transformação radical da sociedade", não para restaurarmos o que tínhamos antes do neoliberalismo, mas para construir algo novo, ou seja, "a fundação de uma nova ordem pela invenção de instituições políticas destinadas a subverter a estrutura da sociedade". Para os autores um projeto dessa dimensão

só pode ser concebido se for articulado a práticas de natureza muito diversas, isto é, econômicas, sociais, políticas e culturais. Se acabarem por despontar suficientes linhas de força comuns, graças aos atores dessas práticas, poderá cristalizar-se uma "significação imaginária" que dê sentido àquilo que até então parecia não 
passar de ações ou posicionamentos dispersos, dispares ou até mesmo marginais (Dardot; Laval, 2017a, p. 614-615).

Nas últimas décadas emergiram vários movimentos que colocaram a "imaginação política para trabalhar" fazendo uma forte resistência à racionalidade neoliberal e mostrando que "um outro mundo é possível". Na educação também observamos um forte movimento de resistência às tentativas de controlá-la mediante mecanismos gerencialistas e performativos e de negar sua função pública, "comum”, para transformá-la em mercadoria. No campo da formação de professores, como apresentamos a seguir, é exemplar a luta do Movimento dos Educadores brasileiros que, organizados em torno de algumas entidades, principalmente da Associação Nacional pela Formação dos Profissionais da Educação (ANFOPE), vêm propondo, desde a década de 1980, uma Base Comum Nacional (BCN), centrada na docência e referenciada numa concepção sócio-histórica, com o objetivo de formar professores com autonomia intelectual, moral e técnica para conduzir seu trabalho de modo comprometido com a democracia e a justiça social e, assim, produzir em comum o comum.

\section{A razão de mercado conduzindo as políticas de formação de professores}

Iniciamos essa seção problematizando o papel do Estado na elaboração das políticas educacionais, ator importante no cenário em movimento. Até pouco tempo, as políticas educacionais eram vistas como resultado da ação autônoma do Estado, mediando complexas e contraditórias relações de classe. Porém, seu lugar na elaboração das políticas foi se modificando nas últimas décadas. Já Afonso (2001, p. 16) alerta que, não obstante as evidências de um enfraquecimento do Estado, produzido pelo processo de globalização do capitalismo, "continua a ser necessário fazer referência ao papel e lugar do Estado-nação, mesmo que seja para melhor compreender a sua crise atual e a redefinição do seu papel". Na nova fase de acumulação capitalista, que ganhou força a partir da década de 1970, ocorreram mudanças intensas não só no sistema produtivo, mas também nas relações políticas, sociais e culturais. O Estado tem sido submetido, cada vez mais, aos interesses do capital. Progressivamente o Estado-providência, que no pós-guerra teve protagonismo com as políticas públicas de bem-estar social, sucumbe à imposição de um Estado mínimo, gerencialista, que repassa para os indivíduos e a iniciativa privada a responsabilidade pelo bem-estar individual e coletivo.

Se no modelo anterior de Estado tínhamos uma organização mais burocrática, com divisão hierárquica e especializada do trabalho, paulatinamente esse modelo é substituído por "um modelo gerencial, cuja essência é uma administração fundamentada em estratégias empresariais competitivas, mais descentralizada, ágil e capaz de controlar os resultados com vistas à elevação da eficiência e 'qualidade' dos serviços oferecidos" (Cunha; Marcondes; Leite, 2015, p. 687). Nessa perspectiva, Ball (2005, p. 112) identifica o modelo de Estado avaliador, 
"que promove também um novo quadro ético e um modo geral de regulação auto-regulada muito mais 'autônoma'". Modificam-se as maneiras como o Estado exerce o poder, implementando a forma gerencial de governo, através da introdução, no âmbito das políticas, da cultura de performatividade, com a intenção de incutir nos trabalhadores uma atitude de responsabilidade pelo seu bem-estar e o da empresa/local em que trabalham. Nesse novo modelo de organização, os sujeitos são governados/geridos para se sentirem "continuamente responsabilizados e constantemente vigiados" (Ball, 2001, p. 110).

No predomínio da razão neoliberal “o que está em jogo é nada mais nada menos que a forma da nossa existência, isto é, a forma como somos levados a nos comportar e nos relacionar com os outros e conosco mesmo" (Dardot; Laval, 2016, p. 16, grifo nosso). É uma racionalidade econômica e política que influencia os modos como nos relacionamos com o mundo e com os outros, a maneira como vivemos, produzindo assim, certas subjetividades, ou seja, a maneira como nos produzimos como sujeitos. A forma como o neoliberalismo exerce seu poder sobre a sociedade e sobre os indivíduos se apoia em discursos, práticas e dispositivos de coerção ou governamento que se dão através da potencialização e generalização das situações de concorrência e do estabelecimento da empresa como modelo de subjetivação.

Com o novo gerencialismo, o Estado passou a ter a função de expandir o mercado para além do próprio mercado, promovendo o que Dardot e Laval (2016, p. 378) chamam de "ordem-quadro" a partir da intensificação do princípio da concorrência e, também, de supervisionar o "quadro geral" para que a governamentalidade neoliberal seja respeitada por todos os agentes econômicos e sociais. Assim, o neoliberalismo governa todos os indivíduos de forma indireta através de dispositivos que guiam, primeiramente, a própria conduta do sujeito em relação a si mesmo. Nesse novo jogo simbólico, o mais importante não é o valor criado pela força de trabalho no processo de produção, mas sim, o valor "que o indivíduo se torna em si mesmo" e que precisa ser valorizado e perseguido permanentemente, ao longo de toda a vida. O indivíduo torna-se um empreendedor de si mesmo.

Ball (2006) afirma que o neoliberalismo criou um ambiente moral novo em que a ética é encarada numa perspectiva individual, provocando uma depreciação e negação de concepções morais relativas à esfera pública, criticando a ideia de planejamento estatal e de construção e provimento do bem-estar coletivo. Explica, então, que para os neoliberais, "tanto unionismo quanto profissionalismo-burocrático são vistos como fatores que contribuem para as 'falhas' do sistema planejado de provisão pública e como os maiores obstáculos no caminho do desenvolvimento de mercados sociais 'efetivos"' (Ball, 2016. p. 14). Em função disso, observou ele e nós confirmamos no presente de nosso País um ataque permanente às organizações coletivas, ao movimento operário, sindicatos, enfim, a todos os movimentos que ligam o sujeito a um projeto de construção coletiva, a uma visão de destinos comuns possíveis.

Nessa dinâmica, o gerencialismo se constituiu na forma predominante de gestão da sociedade como um todo e da educação em particular, com a introdução de incentivos à moda do mercado, relacionados a performance e responsabilização - i.e., accountability. Por conseguinte, são derivadas novas "subjetividades profissionais". "Não é simplesmente que o que nós fazemos mudou; quem nós somos, as possibilidades para quem nós deveríamos nos 
tornar também mudaram" (Ball, 2006, p. 18). A pesquisa e a análise das políticas públicas, as políticas em educação, de modo especial, precisam levar em conta esse contexto, sob o risco de falsear a realidade ou se submeter a esta nova governamentalidade sem se dar conta.

As reformas na educação fazem parte deste cenário, sustentadas principalmente pelo Banco Mundial, pela UNESCO e OCDE, criaram, conforme Ball (2002, p. 4), um "ambiente de devolução" que tem como tecnologias políticas a forma do mercado e como regra a capacidade de gestão e a performatividade. Essas tecnologias são postas como alternativas à tradição política esteiada no Estado e no bem-estar social. "Elas são colocadas em confronto e comparadas com as velhas tecnologias do profissionalismo e da burocracia". Segundo o autor, é nesse movimento que os mencionados organismos introduziram, nas políticas educacionais, "os terrores da performatividade", definidos como "uma tecnologia, uma cultura e um modo de regulação que se serve de críticas, comparações e exposições como meios de controlo, atrito e mudança" (Ball, 2002, p. 4).

A educação se tornou "insumo" essencial para a competitividade capitalista e em função disso, a formação de professores foi assumindo lugar de destaque para garantir esta competitividade. Por isso, passou a ser objeto de políticas que visam torná-los mais adequados aos novos interesses e valores do mercado.

As organizações internacionais, ao terem evidências de que os professores são fator de grande impacto no processo de aprendizagem dos alunos, vêm colocando a formação de professores na centralidade das reformas educacionais. Nos últimos anos, a OCDE tem feito muitos movimentos para situar a formação docente na agenda das reformas educacionais e promovido as Cúpulas Internacionais sobre a Profissão Docente. Para Oliveira (2020), são as orientações políticas propaladas nesses encontros, através de relatórios e dados estatísticos, que chegam nos mais diferentes países como "evidências de práticas políticas eficazes", reproduzem as concepções de cunho economicista deste organismo, em que "os valores defendidos são de uma educação competitiva, que se organize por meio de instrumentos que sejam eficazes para medir os progressos e que premie os mais competentes". As cúpulas, através da difusão de práticas de "boa docência", alimentam a lógica "competitiva e meritocrática" que progressivamente "vai se instalando como lógica hegemônica na qual os números expressam 'verdades' e classificam sujeitos e instituições" (Oliveira, 2020, p. 96).

Segundo Zeichner (2008, p. 15), assistimos, nas últimas décadas, a fortes tentativas de instalação de programas e projetos cujo modelo de formação de professores segue a agenda da desregulamentação "sugerida" pelos grandes organismos internacionais (BM, UNESCO, OCDE), que tem o objetivo de sujeitar/flexibilizar a formação de professores às forças de mercado, sob argumento de que a competição aumentará a qualidade. O predomínio da perspectiva neoliberal na elaboração das políticas para a educação e, consequentemente, para a formação de professores, imprimiram uma lógica meritocrática de desregulamentação que pretende formar professores "práticos". Estas políticas, como dissemos, vem disputando a alma do professor e produzindo novas subjetividades profissionais, não simplesmente porque mudou o que é ser professor, mas porque está mudando o que o professor faz e, também, aquilo que o professor poderá ser. É a subjetividade do professor que está sendo disputada nesse jogo. 


\section{As políticas educacionais e as novas subjetividades docentes}

Com reflexões de autores como Ball (2002, 2005, 2006), Maguire (2013), Zeichner (2008), Bernstein (2003), Dias (2014) e Cunha, Marcondes e Leite (2015), pretendemos mostrar que as reformas gerencialistas na educação não propõem somente mudanças técnicas ou estruturais, mas mudanças que têm a intenção de reformar também os professores, mudar o significado de ser professor, alterando de forma significativa a identidade social do professor.

Vimos que, à medida que o neoliberalismo impôs o mercado como razão do mundo, o gerencialismo e a performatividade se tornaram as tecnologias políticas de gestão da sociedade, predominantes como um todo e da educação de modo particular; que as reformas promovidas por essa nova racionalidade se apresentam como alternativas mais eficazes do que aquelas centradas no Estado de bem-estar; e que as reformas introduziram políticas de incentivos na forma do mercado em todos os campos das atividades sociais.

$\mathrm{Na}$ maioria dos relatórios dos organismos internacionais, que propõem as reformas, os professores, ditos incompetentes e ineficientes, são considerados os principais responsáveis pelo baixo desempenho do aluno, da escola e do sistema social como um todo. Em função desse diagnóstico, Maguire (2013, p. 39) identifica uma mobilização mundial com vistas à formação de 'um 'novo' professor, para a 'nova' ordem mundial. A solução apresentada pelos reformadores a esse problema indica que governos e legisladores, "de forma técnica", determinem o que os professores devem ensinar, como ensinar e de que forma eles e os seus alunos devem ser avaliados. Há, nitidamente, uma pressão para regular e controlar a produção social do professor e o trabalho do professor, no sentido de seus interesses.

Observando as mudanças na formação de professores, que ocorreram recentemente em alguns países como EUA, Canadá, Nova Zelândia, Austrália e em países da Europa e da Ásia, Maguire (2013, p. 80) constata que buscaram estabelecer essas novas diretrizes e adotaram uma lista de competências para formação inicial dos professores e para o seu recrutamento. Centradas nas práticas de sala de aula, estas diretrizes passaram a indicar aquilo que consideram ser "as melhores práticas" da atividade docente. Há uma clara opção por priorizar as habilidades técnicas e a experiência dos professores, colocando em segundo plano compromissos políticos, valores de desenvolvimento social e cultural e projetos de vida coletivos. As reformas pretendem o professor "como um técnico do Estado, treinado para transmitir um currículo nacional". A prioridade é fazer com que os professores cumpram as diretrizes, as competências estabelecidas e não pensem criticamente as suas práticas; devem "focalizar em ensinar em vez de em aprender; fazer em vez de pensar; habilidades em vez de valores”. Esses são os principais preceitos dos reformadores guiados pela razão do mercado.

Embora as reformas neoliberais não tenham um texto fundamental onde sejam explicitadas as suas prescrições, elas se tornam claras e influentes a partir de um conjunto de publicações com orientações, avaliações e critérios para o financiamento. De maneira geral, essas recomendações não se comprometem com a formação de um professor com autonomia intelectual para conduzir a sua prática pedagógica. O que pretendem, segundo Maguire (2013, p. 82), é produzir "muito mais um gerente empresarial que um intelectual orgânico". 
Conquanto a tradução dessas políticas não seja um processo homogêneo, pois têm peculiaridades nos diferentes espaços nacionais, podemos observar resultados muito parecidos como: dificuldades de atrair e manter os professores no magistério; improvisações e aligeiramento no processo de formação; grande rotatividade de professores nas escolas de periferia e nas que apresentam maiores desafios para a docência, para onde acabam indo os menos experientes e menos qualificados; grande flexibilidade na atuação e na contratação de professores, resultando numa alta descartabilidade destes sujeitos.

Neste contexto, a estabilidade de uma carreira de longo curso, como um projeto de vida em serviço público, que a profissão conquistou na segunda metade do século $\mathrm{XX}$, em muitos países, está sendo desmantelada. Em seu lugar está sendo posta a cultura da empresa, da performatividade, do Estado avaliador, que submete o professor a um jogo de pressão permanente para produzir resultados, sem reconhecimento social.

Diante deste cenário nos perguntamos: de que forma estas políticas gerencialistas, centradas na performatividade estão influenciando a produção de novas identidades docentes? Observamos que, à medida que houve a flexibilização do trabalho docente, formas de contratação menos burocráticas, desmantelamento das carreiras e enfraquecimento da atuação dos sindicatos, os professores ficaram sujeitos às regras de competição estabelecidas pelo Estado-avaliador e passaram a seguir os preceitos do mercado. Ficaram cada vez mais sujeitos a um jogo competitivo, à avaliação profissional contínua e a novas formas de controle que vão progressivamente determinando a sua nova forma de ser.

Com essas mudanças, Ball (2004, p. 13) observa os professores cada vez mais envolvidos numa nova "cultura de performatividade competitiva" que tem o papel de construir uma governamentalidade com o objetivo de tornar o professor um técnico a serviço da eficiência e da produtividade. Por que interessa aos reformadores submeter os professores a essa nova cultura performativa?

[...]facilita o papel de monitoramento do Estado, "que governa a distância" "governando sem governo". Ela permite que o Estado se insira profundamente nas culturas, práticas e subjetividades das instituições do setor público e de seus trabalhadores, sem parecer fazê-lo. [...] Os discursos da responsabilidade (accountability), da melhoria, da qualidade e da eficiência que circundam e acompanham essas objetivações tornam as práticas existentes frágeis e indefensáveis - a mudança torna-se inevitável e irresistível, mais particularmente quando os incentivos estão vinculados às medidas de desempenho. (Ball, 2004. p. 13)

Mediante este esclarecimento, retomamos que com esses mecanismos as reformas vão consolidando o gerencialismo e a performatividade como tecnologias políticas principais para formar e guiar os novos professores, transformando-os em empreendedores. As leituras que são difundidas, de um sistema de avaliação nacional que poderia ter a finalidade subsidiar o planejamento e reflexões dos professores, acabam por classificá-los como bem-sucedidos ou fracassados. Nesse novo ambiente é cada vez mais necessário produzir indicadores, tabelas classificatórias, tanto no âmbito local, nacional ou internacional, para criar 
comparações e disputas que, por si só, elevam as apostas neste jogo cada vez mais competitivo e, também, mais raso. Criam uma política de números que, segundo Oliveira (2020, p. 96) “expressam 'verdades' e classificam sujeitos e instituições”. São essas novas tecnologias de comparação, mensuração e responsabilização que estão governando a educação e os professores, dando outro sentido ao que é ensinar e como ensinar, determinando a forma como os professores pensam e se relacionam com os outros.

Para Maguire (2013, p.81), a possibilidade de o professor ser um profissional autêntico e autônomo, neste novo modelo reformista, é mínima, porque os professores estão cada vez mais submetidos a currículos e metodologias preestabelecidas. O novo profissionalismo produz um professor colonizado, definido pela sua performatividade e flexibilidade, um seguidor de regras, pois o que conta na prática profissional é satisfazer a decisões tomadas externamente, geralmente relacionadas ao cumprimento de metas. Essas tecnologias performativas produzem nos professores um sentimento de inautenticidade, de perda da autonomia.

A partir da experiência britânica que foi o principal modelo para as reformas que se espalharam pelo mundo, desde a década de 1980, Ball (2002, p. 4-5) fez um exercício investigativo e analítico para mostrar que as tecnologias políticas das reformas educacionais "não são simplesmente veículos para a mudança técnica e estrutural das organizações, mas também mecanismos para 'reformar' professores e para mudar o significado de ser professor". Portanto, as reformas disputam a "alma do professor".

Embora as reformas propostas pelos organismos internacionais se apresentem com o propósito de desregulamentação, de flexibilização e de concessão de autonomia aos gestores, segundo Ball (2002), elas são processos de "re-regulação", porque o Estado, neste novo contexto, não abre mão do controle, apenas estabelece novas formas de controle, produz uma nova forma de regulação "menos visível", mas centrada nos sujeitos, "auto-regulada". Introduzem, assim, uma cultura de performatividade na qual "os professores são representados e encorajados a reflectir sobre si próprios como indivíduos, que fazem cálculos sobre si próprios, 'acrescentam valor' a si próprios, aumentam sua produtividade" (Ball, 2002, p. 6). Essa performatividade a que é submetido o professor tem dois efeitos aparentemente conflitantes:

um aumento da individualização, incluindo a destruição de solidariedades baseadas numa identidade profissional comum, e a filiação em sindicatos, contra a construção de novas formas institucionais de filiação e "comunidade", baseada numa cultura de empresa. Isto envolve o "re-trabalhar" das relações entre o comprometimento e empenhamento individuais e a acção na organização, aquilo a que Willmott (1993, p. 517) chama "a governação da alma dos empregados" (grifos nossos). (Ball, 2002, p. 9)

As antigas formas de identificação dos professores como uma categoria profissional, que tinha corpo e lutas coletivas, foram sendo desprezadas pela ação dos reformadores e paulatinamente substituídas por novas formas construídas a partir da cultura da empresa. Em 
outro texto, Ball (2006) afirma que, com as reformas, o professor é afetado por um forte sentimento de incerteza, de culpa, de perda da estabilidade e de autonomia, fazendo emergir uma nova subjetividade ${ }^{2}$, que surge de um longo e intenso processo de "autovigilância", mas, também, de "mútua vigilância". "Neste contexto, a profissionalidade é substituída por responsabilização, coleguismo por competição e comparação interpessoal de performances" (Ball, 2006, p. 15). Progressivamente o profissionalismo desaparece e aparece o professor como prático, desvinculado do contexto social e de uma prática ético-cultural. Assim, segundo Ball (2005, p. 542), perdem a autenticidade, porque são afastados da "reflexão moral", que estabelece o sentido histórico da educação e o seu papel em diálogo com "as coletividades do mundo social”. Desta forma,

[...] o profissionalismo está chegando ao fim, está sendo desalojado de sua "existência precária e resplandecente". Está em curso uma mudança profunda em algumas das "múltiplas forças independentes, que condicionam a formação da identidade profissional dos professores na prática" (Dillabough, 1999, p.390). Essa mudança é tão profunda que, no regime do "pós-Estado de Bem-Estar", o profissionalismo como prática ético-cultural não tem lugar, não tem futuro. (Ball, 2005, p.540, grifos nossos)

Com a ajuda de Bernstein (2003, p.103), podemos dizer que as reformas operam com mecanismos que, desde fora, projetam as "identidades" docentes, retirando a autonomia e corroendo "uma base coletiva" que é substituída por compromissos pragmáticos de curto prazo. Ball (2005, p. 543) chama a isso de "instrumentalismo desengajado", que retira o professor do histórico processo de pertencimento e compromisso com a escola e com a comunidade, exigindo dele um "desligamento de sua experiência social", dos seus vínculos de classe, principalmente com sindicatos e movimentos sociais. Os professores perdem, inclusive, a possibilidade de lutar por respeito, porque não são mais autorizados "a falar por si mesmos em debates públicos sobre sua prática"; o que fala por eles são os números, as estatísticas, o desempenho, a performance. Assim, os professores têm as suas identidades reconstruídas nesse processo em que os

compromissos humanísticos do verdadeiro profissional - a ética do serviço - são substituídos pela teleológica promiscuidade do profissional técnico - o gerente. A eficácia prevalece sobre a ética; a ordem, sobre a ambivalência. Essa mudança na consciência e na identidade do professor apoia-se e se ramifica pela introdução, na preparação do professor, de formas novas de treinamento não intelectualizado, baseado na competência. "Trata-se de uma educação resultante de supostas exigências funcionais ou instrumentais, não de objetivos pessoais, culturais ou políticos" (Muller, 1998, p.188; ver também Ryan, 1998). Durante o treinamento, o professor é "re-construído" para ser um técnico e não um profissional capaz de julgamento crítico e reflexão. Ensinar constitui apenas um trabalho, um conjunto de competências a serem adquiridas (Ball, 2005, p. 548 , grifos nossos) 
O professor como profissional engajado é substituído por um novo modelo, o técnico. Na sua nova forma de atuação, a busca de resultados se sobrepõe à ética e o controle das suas ações à autonomia pedagógica. Esse novo professor vai sendo formado por novos mecanismos de treinamento em habilidades e competências funcionais ou instrumentais, previamente estabelecidos e desvinculados do contexto pessoal, cultural e político do professor. O professor perde seu profissionalismo, ele é treinado e reconstruído para se transformar num técnico. $\mathrm{O}$ ato de ensinar passa a ser um ato mecânico, desprovido de reflexão e crítica, ou seja, ensinar se transforma em um conjunto de competências técnicas adquiridas no treinamento.

Ao reconhecer as mudanças provocadas pelas reformas gerencialistas, promovidas pelos organismos internacionais, que afetam diretamente as políticas de formação de professores em diferentes regiões do mundo, buscando produzir um novo perfil de docentes para esse novo contexto, torna-se importante considerar o contexto brasileiro e seus estudiosos. Consoante, Dias (2014) afirma que essas políticas circulam como textos e discursos, reafirmando o protagonismo dos professores para a melhoria do cenário educacional e que "tal produção destacou o modelo do currículo por competências e a defesa de um perfil profissional docente a ser projetado para o "novo" modelo de professor" (p. 9). Partindo de uma "interpretação discursiva" das políticas curriculares, a autora chama atenção para as múltiplas possibilidades de leitura e interpretação que essas políticas criam e que "os textos das políticas estão abertos a diferentes leituras e interpretações, estando sempre sujeitos a ressignificação por meio de processos de recontextualização por hibridismo" (p. 12). Tendo que a forma como as políticas são significadas é influenciada pelo contexto, dedicamos a próxima seção à maneira singular como, no contexto brasileiro, tais políticas têm atuado para produzir um novo perfil docente.

\section{A configuração da identidade docente no Brasil}

As reformas curriculares propostas nas últimas décadas por organismos internacionais e pelos movimentos que orbitam em torno desse tema têm colocado foco nos professores e na sua profissionalização. Como já comentamos, as pautas dessas reformas, ao reafirmarem a importância dos professores para a melhoria da educação, os colocam como seus próprios protagonistas. Porém, o profissional desenhado por esses organismos é de um técnico/prático incumbido de executar um currículo padronizado, detalhado em competências e habilidades nas quais os estudantes devem ser capacitados, dentro dos critérios gerencialistas e performativos que determinam também aos professores competências e habilidades.

$\mathrm{Na}$ investigação sobre o contexto das políticas de formação de professores no Brasil no qual as disputas em torno do perfil docente se desenvolve, procuramos dar atenção à complexidade e ambivalência dos textos e dos discursos. Tendo presente Dias e Lopes (2003), ao contribuírem com a noção de que diferentes discursos concorrem para a legitimação dessas políticas que não têm um sentido único, mas que se materializam a partir de um complexo processo de hibridização, destacamos: "A incorporação dos diferentes 
discursos nos documentos curriculares é resultado de um complexo processo de negociação, pelos diferentes sujeitos e grupos sociais, de sentidos em torno das políticas” (p. 82). Assim, compreendemos que as disputas e negociações sobre o lugar, o conteúdo e o modelo curricular da formação de professores não ocorrem somente pelo valor estratégico desta política em si, mas porque implicam na institucionalidade desta função social e no poder destes profissionais que, destarte, incidem sobre o lugar, o conteúdo e a forma da Educação Básica. Daí, em determinadas condições sócio-históricas de formação da cidadania e da democracia.

Portanto, salientamos as articulações no processo de definição das políticas de formação de professores, compreendidas em contexto e na sua complexidade, valendo a perspectiva de Dias e Lopes (2003, p. 95):

Acentuamos que esse processo de articulação, marcado por conflitos e disputas, não pode ser pensado a partir de uma posição maniqueísta. As posições acerca da formação docente possuem diferenças significativas e, a despeito de toda a diferença existente, condições políticas favorecem ao estabelecimento de cadeias de equivalência, reunindo questões cujos significantes são diversos, produzindo nexos em meio à complementaridade e à tensão.

No Brasil, a circulação das políticas educacionais gerencialistas e das políticas curriculares homogeneizadoras tem impactado significativamente o currículo e o modelo de formação de professores, conquanto também produzido um forte movimento resistência, cuja disputa central tem sido a identidade/perfil docente numa perspectiva técnica e pragmática. Diante da complexidade desse cenário, para compreender como o perfil docente vem se configurando, em uma perspectiva histórica, tomamos de Cunha, Marcondes e Leite (2015, p. 688) o cuidado de "observarmos como as mudanças estão atreladas aos aspectos sociais, políticos e econômicos que marcaram o contexto do nosso país em diferentes períodos". Assim, essas autoras identificam três movimentos, não estanques cronologicamente, que nas últimas décadas vêm influenciado a formação da identidade dos professores brasileiros: na ditadura militar o professor foi concebido como um "técnico do magistério"; na redemocratização como "trabalhador da educação"; e no contexto das reformas globais como um "profissional" prático.

Explicam ainda que no período da ditadura militar, o professor era visto como um "técnico do magistério". Sua formação estava sustentada "na apropriação de novas metodologias para executar o planejamento de ensino elaborado por especialistas" e visava uma "organização educacional racional capaz de minimizar as interferências subjetivas que pudessem pôr em risco sua eficiência" (Cunha; Marcondes; Leite, 2015, p. 690). Com características semelhantes, na década de 1990, o país iniciou reformas educacionais orientado pelas diretrizes gerencialistas e performativas dos organismos internacionais. O professor passou a ser visto como um "profissional prático" e a construção da identidade dos professores é, mais uma vez, associada a uma "identidade projetada": aquela em que o Estado regula a formação e atuação do professor a partir de uma "racionalidade técnica", com 
a finalidade de atender a demandas externas, de natureza "econômica e tecnológica". As proposições desse período estão focadas em produzir "políticas curriculares centralizadas" para estabelecer as habilidades e competências demandadas a partir de "critérios explícitos e específicos" do mercado.

Sem dúvida, as reformas educacionais introduzidas no Brasil, nos anos 1990, se caracterizavam por propostas curriculares mais centralizadas e padronizadas. Neste período, tivemos a implantação do Sistema de Avaliação da Educação Básica (SAEB), focado nos resultados e num currículo nacional que resultou na aprovação dos Parâmetros Curriculares Nacionais (PCN) em 1997. Neste contexto, o currículo para a formação dos professores também foi reformado com novas normativas publicadas no final dos anos 1990 e início deste século: a Resolução CNE/CP n ${ }^{\circ}$ 04/1997, de orientações gerais para a construção de novas diretrizes curriculares nacionais para os cursos de graduação; o Parecer CNE/CP nº 119/1999, de Referenciais Curriculares para a Formação de Professores e orientações para a criação dos institutos superiores de educação; o Parecer CNE/CP n 09/2001 e a Resolução CNE/CP n 01/2002, que instituíram as Diretrizes Curriculares Nacionais para a Formação de Professores da Educação Básica, em nível superior, curso de licenciatura, de graduação plena.

Neste conjunto de normas que pretendiam modificar o modelo de formação de professores, o conceito de competências ocupava um lugar central na organização dos currículos, com o fito de garantir a qualidade do novo modelo de formação docente. Como ponderam Dias e Lopes (2003, p. 1157), "Nessa concepção, o conhecimento sobre a prática acaba assumindo o papel de maior relevância, em detrimento de uma formação intelectual e política dos professores".

Contudo, esta perspectiva esteve em refluxo durante os governos mais à esquerda, entre 2003 e 2016, mas ganhou novo impulso depois do golpe parlamentar/midiático de 2016 pela aprovação da Base Nacional Comum Curricular (BNCC) mediante as Resoluções CNE/CP $n^{\circ}$ 02/2017 e no 04/2018; assim como das novas Diretrizes Curriculares Nacionais para a Formação Inicial de Professores para a Educação Básica com a Base Nacional Comum para a Formação Inicial de Professores da Educação Básica (BNC-Formação), instituídas pela Resolução CNE/CP n 02/2019; e mais as Diretrizes Curriculares Nacionais para a Formação Continuada de Professores da Educação Básica e respectiva a Base Nacional Comum para a Formação Continuada de Professores da Educação Básica (BNC-Formação Continuada), por meio da Resolução CNE/CP n 01/2020.

Ao situar estes marcos normativos, consideramos que a reforma implementada no Brasil nos anos de 1990 e as modificações deflagradas de 2016 ao presente levam a barateamento e desqualificação da formação docente. Assistimos, à proliferação massiva da formação de professores com projetos bem pragmáticos e desprovidos de uma sólida formação teóricoprática, titulando professores como técnicos com pouca capacidade de intervenção crítica no processo educativo, mormente em instituições privadas - mais de $70 \%$ - e na modalidade a distância, com precariedade de condições acadêmicas e culturais. Este modelo, espraiandose, acaba por minar o campo e vai legitimando a precarização de projetos em universidades públicas, os concursos para o magistério público e a formação continuada. Entretanto, corroborando Cunha, Marcondes e Leite (2015), afirmamos que, no período em que o Brasil 
viveu o processo de luta pela reabertura democrática e logo após, tivemos uma organização e participação política marcante dos professores. Nessa época surgiu o Movimento dos Educadores que, juntamente com outros movimentos sociais e sindicais, lutou por democracia, justiça social e principalmente pelo direito a uma educação pública de qualidade. Disputaram avanços no processo Constituinte de 1987/1988 e no projeto da nova Lei de Diretrizes e Bases da Educação Nacional, na elaboração dos planos nacionais de educação de 2001-2011 e 2014-2024, na legislação do financiamento redistributivo da Educação Básica e das carreiras do magistério, na (re)organização dos sistemas e conselhos de educação dos estados e municípios, entre outros. Uma intensa militância produziu, nos professores, o que Cunha, Marcondes e Leite (2015, p. 689) chamaram de "identidade de trabalhadores da educação", uma "identidade introjetada", fruto do protagonismo docente na resistência e na proposição de políticas, tendo como referência valores de emancipação e justiça social predominantes naquele momento.

A luta do Movimento dos Educadores faz parte da luta mais ampla para superar as contradições e injustiças da sociedade capitalista e seus mecanismos de controle e dominação. Com consciência do seu papel histórico, referenciado em uma concepção sóciocrítica, o movimento construiu compromissos políticos e produções teóricas que resultaram num conjunto de referências para a formação de professores. Esse processo embasa um perfil profissional que vai se estabelecendo a partir de uma prática reflexiva autônoma e intelectualizada. Na perspectiva construída por Dardot e Laval (2017, p. 478), podemos afirmar que, à medida em que enfrenta o modelo tecnicista da ditadura militar e o gerencialismo das reformas neoliberais, o movimento propicia "uma práxis instituinte emancipadora", que consignamos como distinta e potente, porque "faz do comum a nova significação do imaginário social", buscando superar a razão de mercado e seus mecanismos de controle e dominação.

Foi no período de luta pela redemocratização do Brasil que os educadores reorganizaram e criaram as suas entidades representativas. Durli (2007, p. 204) destaca a importância que teve, para o Movimento dos Educadores, a construção de forma autônoma e coletiva, em 1983, da Comissão Nacional de Reformulação dos Cursos de Formação do Educador (CONARCFE), a qual, em 1990, se constituiu na Associação Nacional pela Formação dos Profissionais da Educação (ANFOPE). A realização do I Encontro Nacional de Reformulação dos Cursos de Preparação de Recursos Humanos da Educação, no dia 21 de novembro de 1983, em Belo Horizonte, foi um momento decisivo para o movimento. A programação e os objetivos do encontro tinham sido previamente definidos pelo MEC, porém os professores e os estudantes presentes não concordaram com a metodologia e os objetivos indicados e, no dia seguinte, assumiram a coordenação do Encontro construindo uma nova pauta.

Este ato representou a independência do Movimento, fortalecida, também, pela transformação do Comitê Pró-Formação do Educador em Comissão Nacional de Reformulação dos Cursos de Formação do Educador (CONARCFE). Segundo a Associação... (1992, p. 4), "a Comissão herdou do Comitê o espírito de autonomia 
frente aos órgãos oficiais, bem como seu objetivo de promover a articulação, em nível nacional, dos esforços destinados a reformular os cursos de formação do educador, sistematizando propostas e experiências (Durli, 2007, p.204).

Na sequência, de 1983 a 1990, a CONARCFE intensificou seu trabalho realizando vários eventos nacionais que deram origem ao chamado Movimento dos Educadores, composto por um conjunto de entidades como: a Sociedade Brasileira para o Progresso da Ciência (SBPC), a Associação Nacional de Pós-graduação e Pesquisa em Educação (Anped), o Centro de Estudos Educação e Sociedade (Cedes) e a Associação Nacional de Educação (Ande), entre outras. Com a transformação da CONARCFE na ANFOPE, nos últimos quarenta anos a luta dos educadores por um modelo de formação de professores referenciada numa Base Comum Nacional (BCN), que advoga o protagonismo do professor e um currículo de formação de professores centrado na docência da Educação Básica, vem contribuindo para a emergência de um perfil docente identificado com as lutas dos trabalhadores e com compromisso social.

Essa identidade do professor foi forjada em processos mais autônomos, sem uma política de regulação do Estado e por isso, favoreceu a emergência de modelos de políticas curriculares descentralizadas, cujo objetivo deveria ser o desenvolvimento cognitivo, a valorização cultural e a participação política a partir de critérios curriculares implícitos, múltiplos e difusos (BERNSTEIN, 1996). Em outras palavras, um currículo não expresso formalmente, diversificado e com determinações imprecisas, de modo a enfraquecer a classificação dos sujeitos (Cunha; Marcondes; Leite, 2015, p. 690).

Com os constantes movimentos de resistência, avanços significativos vão despontando já nos anos de 1980, como as discussões voltadas à superação da visão tecnicista, predominante até aquele momento, que concebia a formação de professores como uma mera formação de recursos humanos. Era imperativo, então, imprimir um outro caráter à concepção de profissional da educação, um "caráter sócio-histórico dessa formação", que implica na necessidade de formar "um profissional de caráter amplo", com pleno domínio do conhecimento científico-pedagógico e com capacidade de "compreensão da realidade de seu tempo", por meio do "desenvolvimento da consciência crítica que lhe permita interferir e transformar as condições da escola, da educação e da sociedade" (Freitas, 2002, p. 139).

Há quatro décadas a ANFOPE tem sido protagonista na construção coletiva de pautas que, segundo Durli (2007, p. 205), se apoiam “em princípios que expressam o caráter de resistência e contraposição às ações impositivas oriundas das políticas governamentais". O que unificou essa resistência ao longo do tempo, foi a construção coletiva da Base Comum Nacional (ANFOPE, 1994) para a formação de professores. Nesta, Durli (2007, p. 206) identifica dois sentidos conceptuais complementares: um de natureza mais política "caracterizando-a como instrumento de luta pela formação e carreira do educador" e o outro envolve a concepção de formação do movimento e funciona como "princípio orientador dos currículos dos cursos de formação dos educadores". A BCN tem a docência como princípio básico para a formação dos professores. A docência é o "elemento catalizador de todo o 
processo de formação, pois a partir dela se materializaria o trabalho pedagógico comprometido com a práxis educativa e a unidade teórico-prática" (Durli, 2007, p.210). Este princípio, no entanto, foi objeto de certas divergências no movimento, porque significou a defesa do fim das habilitações especializadas no curso de Pedagogia - o que não era unanimidade.

Mesmo com as divergências, naturais em um processo de construção coletiva, o Movimento dos Educadores consubstanciou, de forma orgânica e coerente, uma base teórica comum e um conjunto de lutas políticas que lhe deu unidade para se contrapor às políticas tecnicistas da ditadura militar e às reformas gerencialistas e performativas da década de 1990 e início dos anos 2000. Dourado (2013, p. 376) observou que, à medida que a concepção de $\mathrm{BCN}$ foi se consolidando, passou a ter "uma forte incidência sobre a docência e o trabalho pedagógico como núcleo constitutivo e constituinte da formação" e, assim, foi sendo incorporada nas reformas dos cursos de licenciatura no interior das instituições formadoras. Em alguns momentos, a BCN é "incorporada nos marcos legais, nas políticas e programas direcionados à formação de professores, de maneira articulada ou não, e se constitui em importante ação do movimento de professores" (Dourado, 2013, p.376).

No Brasil, o processo de regulamentação da formação de professores, influenciado pelos valores de eficácia e eficiência vindos do mundo empresarial, via organismos internacionais, teve início, efetivamente, em 1996 com a aprovação da LDB. A partir desta surgiram várias regulamentações e estruturas para adequar a educação e a formação de professores a estes novos princípios e valores. A nova estrutura de formação de professores para a Educação Básica, segundo Scheibe (2008, p. 49), tinha o claro intuito de aumentar as estatísticas referentes aos professores com formação superior e foi responsável por um vertiginoso crescimento da oferta de cursos de formação "aligeirados", de baixa qualidade, principalmente, a distância. Este novo quadro na formação de professores demonstrava o descompromisso do governo com as demandas históricas do movimento dos educadores, que defendia políticas públicas que garantissem uma sólida formação universitária para os professores.

Os programas de formação implementados por estas novas instâncias e formas educativas, simplificam o trabalho pedagógico e descaracterizam a identidade dos profissionais do magistério, superpondo-se à estrutura de formação já existente, e pouco expandida, das universidades brasileiras (Scheibe 2008, p. 49).

Essas proposições sofreram fortes reações do Movimento dos Educadores e das instituições universitárias, principalmente das públicas, porque também separavam instituições superiores de pesquisa das instituições de ensino, rebaixando o valor acadêmico e social da formação dos professores. A resistência conseguiu conter as políticas gerencialistas, principalmente na segunda metade da década de 1990, e influenciou muito a elaboração das diretrizes curriculares para a formação de professores no início deste século, principalmente a Resolução CNE/CP n ${ }^{\circ}$ 01/2006, que instituiu as Diretrizes Curriculares Nacionais para o curso de graduação em Pedagogia e a Resolução CNE/CP nº 02/2015, que 
revogou a Resolução $\mathrm{CNE} / \mathrm{CP} \mathrm{n}^{\circ}$ 01/2002 e definiu novas Diretrizes Curriculares Nacionais para a formação inicial em nível superior (em cursos de licenciatura, cursos de formação pedagógica para graduados e cursos de segunda licenciatura), assim como para a formação continuada.

Ambas normativas, a CNE/CP n ${ }^{\circ}$ 01/2006 e a CNP/CP n ${ }^{\circ}$ 02/2015 valeram-se da Base Comum Nacional, construída pelo Movimento dos Educadores, para estruturar a política normativa da formação de professores para a Educação Básica. Foram elaboradas pelo Conselho Nacional de Educação em processo de ampla colaboração com diversas organizações e pessoas de alto reconhecimento neste campo político-educacional, inclusive dos profissionais da educação escolar. Tinham como princípios norteadores: sólida formação teórica e interdisciplinar, unidade teoria-prática, trabalho coletivo e interdisciplinar, compromisso social e valorização do profissional da educação, gestão democrática, avaliação e regulação dos cursos de formação e uma concepção ampla de docência. A Resolução $\mathrm{CNE} / \mathrm{CP} \mathrm{n}^{\circ}$ 02/2015 indicava, também, a necessidade de as instituições formadoras articularem as licenciaturas em um Projeto Institucional de formação dos profissionais da Educação Básica. Todavia, estas diretrizes iam na contramão das reformas gerencialistas e performativas prescritas pelo mercado através dos organismos internacionais, que logo adiante ascenderam na política brasileira.

Cabe destacar que o cenário em que estas diretrizes foram aprovadas coincide com o período - 2003 a 2016 - no qual o Brasil foi governado por uma coalizão de partidos majoritariamente de esquerda, sob o comando do Partido dos Trabalhadores (PT), que tem uma relação histórica com os movimentos sociais e suas proposições e reinvindicações. $\mathrm{Na}$ medida do possível, atuando estrategicamente na correlação das forças políticas e econômicas, foi possível contrapor as políticas neoliberais, imprimindo avanços significativos nas políticas sociais de inclusão, de modo especial na educação básica e na educação superior, como nos cursos de licenciatura, por meio de significativa expansão do acesso para setores da sociedade que historicamente estavam excluídos desse nível de ensino, de ampliação da diversidade cultural e da gestão democrática nas instituições públicas de ensino.

Porém, as políticas gerencialistas voltaram a ser hegemônicas no Brasil, a partir do golpe que, em 2016, afastou a presidenta Dilma Rousseff e reposicionou no Ministério da Educação (MEC) e no Conselho Nacional de Educação (CNE) a voz e ação das fundações empresariais organizadas em torno do Movimento Todos pela Educação, com posições privatistas e conservadoras. A "razão de mercado" voltou ao comando das políticas educacionais brasileiras, avançando rapidamente em posições estratégicas para consolidar o seu projeto de educação, alinhado com os organismos internacionais. Nessa direção, aprovaram uma Base Nacional Curricular Comum para a educação básica - Resoluções CNE/CP n ${ }^{\circ}$ 02/2017 e no 04/2018 - o Novo Ensino Médio (Lei n ${ }^{\circ}$ 13.415/2017), as novas diretrizes para a formação inicial de professores, a BNC-Formação, ditada na Resolução CNE/CP $\mathrm{n}^{\circ}$ 02/2019, e as diretrizes para a formação continuada, na $\mathrm{CNE} / \mathrm{CP} \mathrm{n}^{\circ}$ 01/2020.

Estas novas diretrizes recolocam a formação de professores no Brasil na órbita das políticas gerencialistas e dos interesses econômicos. Desconsideram o contexto histórico e 
social da realidade brasileira; vinculam a formação de professores a uma racionalidade técnica; subordinam a formação de professores à BNCC e sua ênfase nas competências vinculadas à perspectiva neoliberal da empregabilidade, da concorrência, da exclusão, do individualismo e da autorresponsabilização do sujeito pela sua formação; restringem as competências docentes às dimensões do conhecimento profissional, prática profissional e engajamento profissional; fragilizam, restringem e atrofiam o currículo das licenciaturas, introduzindo conhecimentos fragmentados e utilitaristas com foco na formação de professores práticos, capazes de aplicar os conhecimentos da BNCC; impõem uma lógica meritocrática e de responsabilização, que vincula a formação dos professores diretamente à aprendizagem dos estudantes, com o objetivo de submetê-los a um processo performativo e de avaliação reguladora com responsabilização "accountability".

Assim sendo, consideramos que a BNC-Formação induz a um currículo empobrecido de teoria, reflexão, pesquisa e crítica, atributos imprescindíveis para uma educação emancipadora. Esse modelo de formação docente afasta-se da concepção do professor como um intelectual e da docência como eixo dialógico. Retoma o modelo de formação produzido pelo tecnicismo, na ditadura, e aprofundado pelo modelo gerencialista performativo das reformas neoliberais. Desconsidera a natureza teórico-prática da função docente ao centralizar a aquisição de habilidades e competências práticas. Revela que o interesse maior é produzir professores adequados aos interesses pragmáticos do mercado, ou seja, professores com habilidades técnicas para aplicarem o currículo já prescrito pela BNCC. Isso ficou bem posto no Documento Final do XX Encontro da ANFOPE, em 2021.

As atuais políticas de formação de professores expressam a materialização da reforma empresarial no campo da formação de professores e têm como objetivo a padronização curricular com vistas a aumentar o controle político e ideológico sobre o que se ensina e como se ensina na escola de educação básica e avaliar professores e estudantes em exames nacionais censitários; [...] creditar cursos e autorizar as instituições sintonizadas com a BNC da Formação e, portanto com a BNCC, aprofundando a interferência no trabalho docente universitário e o controle político e ideológico sobre o magistério da educação básica (ANFOPE, 2021, p. 45).

Como procuramos situar ao longo deste artigo, nas últimas quatro décadas, a disputa pela identidade docente nas políticas de formação de professores esteve presente tanto em nível global quanto no âmbito nacional. No Brasil, as reformas em curso recrudesceram essas disputas. As atuais políticas se filiam ao movimento de reformas promovidas pela "razão de mercado", que através do Estado gerencialista opera para produzir, de fora para dentro, uma "identidade projetada", um professor como técnico guiado por processos de controle performativos. Essa lógica corrói a base coletiva do professorado e dos projetos institucionais de formação docente, substituída por desígnios pragmáticos de curto prazo. Não obstante, temos um forte movimento de resistência dos educadores que atribuem à educação escolar, básica e superior, e aos professores papel fundamental na luta por justiça social e na construção de um outro mundo possível. Com esse processo os professores, a partir de um processo reflexivo autônomo e 
intelectualizado, constroem sua identidade à medida que produzem uma "práxis instituinte emancipadora" (Dardot; Laval, 2017, p. 478).

No momento em que, no Brasil, as políticas de formação de professores estão no centro das disputas, é de fundamental importância recuperar a memória das lutas comuns empreendidas pelo Movimento dos Educadores, para aglutinar forças e, assim, contrapor os discursos e práticas dominantes, que com sua "razão de mercado" se apresentam como ilibados e auto evidentes. Atuamos, pois, no pensar a formação dos professores para além desse discurso homogeneizador e pragmático. Não construiremos uma sociedade melhor se a educação e, de modo especial, a formação de professores estiver submissa à força do mercado que vem destruindo as noções e experiências de comum, de democracia, de justiça e de liberdade. O contexto de crise sanitária, econômico-social e política em nosso País, levanos a valorizar a emergência de novos movimentos políticos que têm colocado a "imaginação política para trabalhar". A história mostra que a resistência é possível embora a construção de uma nova realidade seja percurso difícil. Para garantir um sistema educacional democrático e de qualidade é preciso formar professores com autonomia intelectual, moral e técnica; portanto, com legitimidade e condições de trabalho para construir em comum o comum.

Assim justificamos a epígrafe deste artigo, de Dardot e Laval (2017, p.478), afirmando que "A única práxis instituinte emancipadora é aquela que faz do comum a nova significação do imaginário social”. É nossa inspiração na docência que emerge da reflexão para uma contestação da ordem atual.

\section{Notas:}

1. É uma categoria foucaultiana que é empregada por Ball (2010) na mesma perspectiva usada por Mitchell Dean "a noção de governamentalidade implica, primeiro, um projeto para a análise do estado que não mais repouse sobre a justaposição dos níveis micro e macro do poder, e, segundo, uma autonomia conceitual de uma analítica do micro poder e da teoria da soberania (Dean, 1994, p.160)".

2. Empregamos o conceito de subjetividade definido por Ball (2010, p. 19) como "padrões segundo os quais contextos experienciais e emocionais, sentimentos imagens e memórias são organizados para formar a nossa própria imagem, o sentido de nós próprios e dos outros e as nossas possibilidades de existência".

\section{Referências}

AFONSO, Almerindo J. Reforma do estado e políticas educacionais: entre a crise do estado-nação e a emergência da regulação supranacional. Educação \& Sociedade, São Paulo, v. 22, n. 75, p. 15-32, ago. 2001. Disponível em: https://www.scielo.br/j/es/a/CGkRcsCcsynSwtSRsj44LBf/?format=pdf\&lang=pt. Acesso em: 31 ago. 2021.

ANFOPE. Relatório do VII Encontro Nacional da Associação Nacional pela Formação dos Profissionais da Educação. 1994. Disponível em: http://www.anfope.org.br/wp-content/uploads/2018/05/7\%C2\%BAEncontro-Documento-Final-1994.pdf. Acesso em: 24 maio 2019.

ANFOPE. Documento Final do XX Encontro Nacional da ANFOPE. 2021. Disponível em: 
http://www.anfope.org.br/wp-content/uploads/2021/04/20\%E2\%81\%B0-ENANFOPE-\%E2\%80\%93Documento-Final-2021.pdf. Acesso em: 17 ago. 2021.

BALL, Stephen J.; BOWE, Richard. Subject departments and the 'implementation' of National Curriculum policy: an overview of the issues. Journal Of Curriculum Studies, [S.L.], v. 24, n. 2, p. 97-115, mar. 1992. Informa UK Limited. http://dx.doi.org/10.1080/0022027920240201. Disponível em: https://www.tandfonline.com/doi/abs/10.1080/0022027920240201. Acesso em: 31 ago. 2021.

BALL, Stephen J. Education Reform: a critical and post-structural approach. Buckingham: Open University Press, 1994.

BALL, Stephen. Diretrizes políticas globais e relações políticas locais em educação. Currículo Sem Fronteiras, [S.I.], v. 1, n. 2, p. 99-116, jul/dez 2001. Disponível em: https://gestaoeducacaoespecial.ufes.br/sites/gestaoeducacaoespecial.ufes.br/files/field/anexo/ball.pdf. Acesso em: 31 ago. 2021.

BALL, Stephen. Reformar escolas/reformar professores e os terrores da performatividade. Revista Portuguesa de Educação, [S.I.], v. 15, n. 2, p. 3-23, jan. 2002. Disponível em: https://www.researchgate.net/publication/26465008_Reformar_escolasreformar_professores_e_os_terrore s_da_performatividade. Acesso em: 31 ago. 2021.

BALL, Stephen. Performatividades e fabricações na economia educacional: rumo a uma sociedade performativa. Educação \& Realidade, Porto Alegre, v. 35, n. 2, p. 37-55, maio/ago. 2010. Quadrimestral. Disponível em: https://seer.ufrgs.br/educacaoerealidade/article/view/15865. Acesso em: 31 ago. 2021.

BALL, Stephen. Profissionalismo, gerencialismo e performatividade. Cadernos de Pesquisa, [S.I.], v. 35, n. 126, p. 539-564, jul./nov. 2005. https://www.scielo.br/j/cp/a/sHk4rDpr4CQ7gb3XhR4mDwL/?format=pdf\&lang=pt. Acesso em: 31 ago. 2021.

BALL, Stephen. Sociologia das políticas educacionais e pesquisa crítico-social: uma revisão pessoal das políticas e. Currículo Sem Fronteiras, [S.I.], v. 6, n. 2, p. 10-32, jul./dez. 2006. Disponível em: https://www.curriculosemfronteiras.org/vol6iss2articles/ball.pdf. Acesso em: 31 ago. 2021.

BALL, Stephen. Performatividades e fabricações na economia educacional: rumo a uma sociedade performativa. Educação \& Realidade, Porto Alegre, v. 35, n. 2, p. 37-55, maio/ago. 2010. Quadrimestral. Disponível em: https://seer.ufrgs.br/educacaoerealidade/article/view/15865. Acesso em: 31 ago. 2021.

BALL, Stephen J.; MAGUIRE, Meg; BRAUN, Annette. Como as escolas fazem as políticas: atuação em escolas secundárias. Ponta Grossa: UEPG, 2016.

BERNSTEIN, Basil. A Pedagogização do conhecimento: estudos sobre recontextualização. Cadernos de Pesquisa, São Paulo, n. 120, p. 75-110, nov. 2003. Disponível em: https://www.scielo.br/j/cp/a/4yvdC8Tm5P9XYL4jfzCx7zH/?format=pdf\&lang=pt. Acesso em: 31 ago. 2021.

BOWE, Richard; BALL, Stephen; GOLD, A. Reforming education \& changing schools: case studies in Policy Sociology. Londres: Routledge, 1992.

BRASIL. Parâmetros Curriculares Nacionais: Introdução Aos Parâmetros Curriculares Nacionais. Brasília, 1997. Disponível em: http://portal.mec.gov.br/seb/arquivos/pdf/livro01.pdf. Acesso em: 30 ago. 2021.

BRASIL. Resolução CNE/CP $n^{\circ}$ 01, de 2006. Diretrizes Curriculares Nacionais Para O Curso de Graduação em Pedagogia, Licenciatura. Brasília, Disponível em: http://portal.mec.gov.br/cne/arquivos/pdf/rcp01_06.pdf. Acesso em: 03 jul. 2019.

BRASIL. Resolução CNE/CP no 02, de 01 de julho de 2015. Diretrizes Curriculares Nacionais Para A Formação Inicial e Continuada em Nível Superior de Profissionais do Magistério Para A Educação Básica. Brasília, DF, Disponível em: http://portal.mec.gov.br/docman/agosto-2017-pdf/70431-res-cne-cp002-03072015-pdf/file. Acesso em: 03 jul. 2019. 
BRASIL. Resolução CNE/CP n ${ }^{\circ}$ 02, de 2019. Diretrizes Curriculares Nacionais Para A Formação Inicial de Professores Para A Educação Básica. Brasília, 20 dez. 2019. Disponível em: http://portal.mec.gov.br/docman/dezembro-2019-pdf/135951-rcp002-19/file. Acesso em: 30 ago. 2021.

BRASIL. Resolução Cne/Cp n ${ }^{\circ}$ 01, de 2020. Diretrizes Curriculares Nacionais Para A Formação Continuada de Professores da Educação Básica. Brasília, 27 out. 2020. Disponível em: http://portal.mec.gov.br/docman/outubro-2020-pdf/164841-rcp00120/file\#: :text=CONSELHO\%20PLENO,RESOLU\%C3\%87\%C3\%83O\%20CNE\%2FCP\%20N\%C2\%BA\%201\%2C\%20DE\%2027\%20DE\%20O UTUBRO\%20DE,(BNC\%2DForma\%C3\%A7\%C3\%A3o\%20Continuada). Acesso em: 30 ago. 2021.

CUNHA, Viviane Gualter Peixoto da; MARCONDES, Maria Inês; LEITE, Vânia Finholdt Ângelo. Formação da identidade do professor no cenário das políticas locais de centralização curricular: lim. Revista ECurriculum, São Paulo, v. 13, n. 4, p. 683-710, out./dez. 2015. Disponível em: https://revistas.pucsp.br/curriculum/article/view/25198/0. Acesso em: 31 ago. 2021.

DARDOT, Pierre; LAVAL, Christian. A nova razão do mundo: ensaio sobre a sociedade neoliberal. São Paulo: Boitempo, 2016.

DARDOT, Pierre; LAVAL, Christian. Comum: ensaio sobre a revolução do século XXI. São Paulo: Boitempo, 2017 a.

DARDOT, Pierre; LAVAL, Christian. O Comum é a revolução, dizem Dardot e Laval. Outras Palavras. São Paulo, p. 1-18. 24 out. 2017b. Disponível em: https://outraspalavras.net/pos-capitalismo/o-comum-e-arevolucao-dizem-dardot-e-laval/. Acesso em: 26 nov. 2021.

DIAS, Rosane Evangelista; LOPES, Alice Casimiro. Competências na formação de professores no Brasil: o que (não) há de novo. Educação \& Sociedade, Campinas, v. 24, n. 85, p.1155-1177, dez. 2003.

DIAS, Rosanne Evangelista; LOPES, Alice Casemiro. Sentidos da prática nas políticas de currículo para a formação de professores. Currículo Sem Fronteiras, [s. 1], v. 19, n. 02, p. 79-99, jul/dez. 2009. Disponível em: https://www.curriculosemfronteiras.org/vol9iss2articles/dias-lopes.pdf. Acesso em: 28 nov. 2021.

DIAS, Rosanne Evangelista. "Perfil" profissional docente nas políticas curriculares. Revista Teias, Rio de Janeiro, v. 15, n. 39, p. 09-23, 2014. Disponível em: https://www.epublicacoes.uerj.br/index.php/revistateias/article/view/24479. Acesso em: 26 nov. 2021.

DOURADO, Luiz Fernandes. A formação de professores e a base comum nacional: questões e proposições para o debate. RBPAE, Porto Alegre, v. 29, n. 2, p. 367-388, maio/ago. 2013. Disponível em: https://seer.ufrgs.br/rbpae/article/view/43529. Acesso em: 01 set. 2021.

DURLI, Zenilde. O movimento nacional pela reformulação dos cursos de formação do educador: embates na construção de um projeto coletivo de formação. In: NASCIMENTO, Antonio Dias; HETKOWSKI, Tânia Maria (org.). MEMÓRIA E FORMAÇÃO DE PROFESSORES. Salvador: Dufba, 2007. p. 198-218. Disponível em: http://books.scielo.org/id/f5jk5/pdf/nascimento-9788523209186-13.pdf. Acesso em: 01 set. 2021.

FOUCAULT, Michael. Nascimento da biopolítica: curso dado no Collège de France (1978-1979). São Paulo: Martins Fontes, 2008.

FREITAS, Helena Costa Lopes de. Formação de professores no Brasil: 10 anos de embate entre projetos de formação. Educação \& Sociedade, Campinas, v. 23, n. 80, p. 133-167, set. 2002. Disponível em: https://www.scielo.br/j/es/a/hH5LZRBbrDFKLX7RJvXKbrH/?format=pdf\&lang=pt. Acesso em: 01 set. 2021.

MAGUAIRE, Meg. Para uma sociologia do professor global. In: APPLE, Michael; BALL, Stephen; GANDIN, Luís Armando (org.). Sociologia da educação: análise internacional. Porto Alegre: Penso, 2013. p. 77-88.

MAINARDES, Jeferson. Entrevista com o Professor Stephen Ball. Olhares, Guarulhos, v. 3, n. 2, p. 161-171, set. 2015. Disponível em: https://periodicos.unifesp.br/index.php/olhares/article/view/432. Acesso em: 01 
set. 2021.

OLIVEIRA, Dalila Andrade de. Políticas itinerantes de educação e a reestruturação da profissão docente: o papel das cúpulas do OCDE e a sua recepção no contexto brasileiro. Currículo Sem Fronteiras, [S.I.], v. 20, n. $1, \quad$ p. $\quad 85-107, \quad$ jan./abr. 2020. Disponível em: https://www.curriculosemfronteiras.org/vol20iss1articles/oliveira.pdf. Acesso em: 01 set. 2021.

SCHEIBE, Leda. Formação de professores no Brasil: a herança histórica. Retratos da Escola, Brasília, v. 2, n. 2, p. 42-53, 2008. Anual. Disponível em: http://retratosdaescola.emnuvens.com.br/rde/article/view/123. Acesso em: 01 set. 2021.

ZEICHNER, Kenneth M. Formação de professores para a justiça social em tempos de incerteza e desigualdades crescentes. In: ZEICHNER, Kenneth M.; DINIZ-PEREIRA, Emílio (org.). Justiça social: desafio para a formação de professores. Belo Horizonte: Autêntica Editora, 2008. p. 11-34.

\section{Correspondência}

Derlan Trombetta: Professor Assistente da Universidade Federal da Fronteira Sul (UFFS), atuando no curso de Pedagogia. Doutorando em Educação (PPGEdu/UFRGS), cursou o Mestrado em Educação nas Ciências e a graduação em Pedagogia na UNIJUÌ e a graduação em Filosofia na PUC-PR. Membro da coordenação da ANFOPE-SC.

E-mail: derlan.trombetta@uffs.edu.br

Maria Beatriz Luce: Maria Beatriz Luce: Professora Titular de Política e Administração da Educação na Universidade Federal do Rio Grande do Sul, é docente permanente dos programas de pós-graduação em Educação da UFRGS e da Universidade Federal do Pampa.

E-mail: lucemb@ufrgs.br

Texto publicado em Currículo sem Fronteiras com autorização dos autores. 